\title{
A look at the last five years of the Sri Lanka Journal of Child Health
}

\author{
Sri Lanka Journal of Child Health, 2015; 44(1): 1-2
}

(Key words: Sri Lanka Journal of Child Health; submitted articles)

The Sri Lanka Journal of Child Health is the Official Quarterly Publication of the Sri Lanka College of Paediatricians (Print ISSN 1391-5452 eISSN 2386$110 \mathrm{x})$. The Journal is published in March, June, September and December and only articles on paediatric subjects are accepted by the Journal. The Editorial Board consists of two Joint Editors and a five member Editorial Committee. The Editorial Office is at Wijerama House, No. 6, Wijerama Mawatha, Colombo 7, Sri Lanka.
The Journal website URLs are $<\underline{\text { http://www.slcp.lk }>}$ and $\quad$ http://www.sljol.info/index.php/sljch $>$. The Journal is indexed with SciVerse Scopus, IMSEAR and is available in Google and Google Scholar.

We have published 20 issues during the period from July 2009 to July 2014. This documentation is a record of some of the important details about the publication over that five year period. The breakdown of the articles over the last five years is shown in Table 1:

Table 1: Articles published in the Sri Lanka Journal of Child Health from July 2009 to July 2014

\begin{tabular}{|l|c|l|c|}
\hline \multicolumn{1}{|c|}{ Type of article } & Number & \multicolumn{1}{c|}{ Type of article } & Number \\
\hline Editorials & 20 & Case Reports published & 56 \\
\hline Leading Articles & 09 & Case Reports awaiting publication & 23 \\
\hline Presidential Addresses & 06 & Picture Stories published & 28 \\
\hline Orations & 04 & Picture Stories awaiting publication & 11 \\
\hline Position Statements and Guidelines & 01 & Point of View & 03 \\
\hline Current Practice & 16 & Snippets from the World Wide Web & 15 \\
\hline Original Articles published & 68 & Book Reviews & 01 \\
\hline Original Articles awaiting publication & 20 & Paediatric Crossword Puzzles & 20 \\
\hline Short Reports published & 12 & Letters to the Editor & 03 \\
\hline Short Reports awaiting publication & 00 & Obituaries & 03 \\
\hline
\end{tabular}

Of the 88 original articles, 60 were entirely Sri Lankan, 2 were combined (Sri Lanka + UK), 15 were from India, 3 were from Nigeria, 2 were from Bangladesh and one each from Pakistan, Thailand, Iran, Turkey, Australia and China.

Of the 12 short reports, 9 were entirely Sri Lankan, one was an audit in UK carried out by a Sri Lankan, one was from India and one was from Nepal. Of the 79 case reports, 44 were Sri Lankan and 35 were Indian. Of the 39 picture stories 12 were Sri Lankan, 26 were Indian and one was Nigerian.

Total number of "New Articles" which is the total collection of Original Articles, Short Reports, Case Reports and Picture Stories, submitted to the Editorial Board of the Sri Lanka College of Paediatricians during the study period, was 308 . All 308 articles were anonymously reviewed by two or more reviewers. Only the two Joint Editors knew the identity of the authors. Most reviewers were members of the Editorial Board. In certain cases, whenever it was thought to be appropriate, reviews were secured from paediatric ultra-specialists such as nephrologists, neurologists, cardiologists, intensivists, surgeons etc.

The Editorial Board met once a month and all final decisions on acceptance or rejection of articles were taken by them at these monthly meetings. The number of articles accepted for publication during the period of review was $218(70.8 \%)$ and the number of articles rejected was $90(29.2 \%)$

The number of original articles published in each issue of the journal has progressively increased from two in the September 2009 issue to five in the June 2014 issue. The number of case reports have increased from two in the September 2009 issue to four in the June 2014 issue and the number of picture stories have increased from one in the September 2009 issue to two in the June 2014 issue. The December 2014 issue of the journal includes five original articles, four case reports and two picture stories.

One could justifiably say that there has been significant and progressive improvement in the many 
and varied aspects of this journal. This is the only journal in Sri Lanka which is dedicated exclusively to documenting material related to child health. From an academic perspective, the Joint Editors, Editorial Board Members and the Publisher have tried steadfastly to maintain satisfactory and best possible standards of publishing. Perhaps as a result of these endeavours, it has been possible to secure indexing of the journal in SciVerse Scopus and IMSEAR, during the period under review.

The Sri Lanka College of Paediatricians also wishes to place on record its deepest appreciation of the support received from the International Network for Availability of Scientific Publications (INASP) of Oxford, UK, in incorporating and publishing the journal in a free-access, free full text, electronic format in the Sri Lanka Journals On-Line (SLJOL) e-portal. That venture has significantly improved the global visibility of the journal.
It is hoped that the hard work that has gone into the publication of the journal will be rewarded by the journal being recognised by other indexing domains in the near future.

G N Lucas and B J C Perera

Joint Editors of Sri Lanka Journal of Child Health 